\title{
Mating systems and interfertility of swamp milkw eed (Asclepias incarnata ssp. incarnata and ssp. pulchra)
}

\author{
CHRISTOPHER T. IVEY*†, SARA R. LIPOW $\uparrow \&$ ROBERT WYATT \\ $\dagger$ Department of Botany, University of Georgia, Athens, GA 30602, U.S.A and ¥Institute of Ecology, University of \\ Georgia, Athens, GA 30602, U.S.A.
}

\begin{abstract}
We investigated the breeding system and interfertility of both subspecies of Asclepias incarnata. We performed hand-pollinations in the glasshouse to compare fruit-set from self- vs. crosspollinations and to assess interfertility in crosses between the subspecies. We also used horizontal starch-gel electrophoresis to infer mating-system parameters from open-pollinated progeny arrays in three natural populations over two consecutive years. Plants of ssp. incarnata were about $1 / 6$ as likely to mature hand self-pollinated fruits as were ssp. pulchra plants. Furthermore, plants varied significantly in both self- and cross-fertility. Fertile offspring resulted from intersubspecific crosses, but hybrid plants showed reduced pollen fertility relative to parental plants, which is similar to what has been reported for wider hybrid crosses among milkweeds. Reduced pollen fertility in hybrids, along with geographical barriers, may contribute to maintaining subspecific differentiation. Based on allozyme markers, naturally pollinated populations were largely outcrossed $\left(t_{\mathrm{m}}\right.$ ranged from 0.881 to 0.986$)$. Plants varied significantly with respect to outcrossed male fertility ( $r_{\mathrm{p}}$ ranged from 0.186 to 0.396$)$ but not self-fertility $\left(r_{\mathrm{t}}\right.$ was not significantly different from 0$)$. Outcrossing rate did not differ significantly among populations or between years. We found swamp milkweed to be neither fully self-compatible nor self-incompatible, which adds to growing evidence of the complexity of milkweed breeding systems. Variation in frequencies of alleles modifying the expression of the self-incompatibility system could explain some of this complexity.
\end{abstract}

Keywords: Asclepias incarnata, intersubspecific hybridization, mating system, milkweed, outcrossing, self-compatibility.

\section{Introduction}

Many hermaphroditic plant species possess physiological mechanisms to prevent the development of self-fertilized offspring, presumably to avoid inbreeding and the diminished fitness that often results (Charlesworth \& Charlesworth, 1987). The evolutionary transition from self-incompatibility to self-compatibility, however, is one of the most common in flowering plants (Stebbins, 1974). This transition has been shown to influence aspects of plant biology ranging from floral morphology (Wyatt, 1988) to population genetic structure (Hamrick \& Godt, 1990). Understanding the evolution of self-fertilization has therefore been an

*Correspondence and present address: Organization for Tropical Studies, A.P. 676-2050, San Pedro, Moutes de Oca, Costa Rica. E-mail: chrisivey@ots.ac.cr important focus of many studies of plant biology (Jarne \& Charlesworth, 1993).

There has been considerable progress in theoretical studies of mating system evolution, but empirical studies, unfortunately, have failed to keep pace (Jarne \& Charlesworth, 1993). Theoretical developments, however, are facilitated by the insights into the biological complexity of mating behaviour in nature provided by empirical work. Studies within groups in which there are historical reports of variation in self-fertility can be especially enlightening, as such variation is essential for evolutionary change.

The milkweed genus (Asclepias) is one such group. Most early workers believed that all milkweeds are self-incompatible (e.g. Hildebrand, 1866), but in $A$. incarnata (Fischer, 1941) and $A$. syriaca (Stevens, 1945), later workers reported successful hand self-pollinations. Other investigators, however, found $A$. syriaca (Sparrow \& Pearson 1948) to be 
self-incompatible. Wyatt \& Broyles (1994) reviewed the data on milkweed reproduction and concluded that breeding systems in Asclepias fall into two classes: those that are largely or completely selfincompatible and those that are largely or entirely self-compatible. Nevertheless, some species regarded as self-incompatible have been found to express low levels of self-fertility (Wyatt, 1976; Wyatt et al., 1996).

To date, evidence for self-compatibility in milkweeds has come from hand self-pollinations conducted under controlled glasshouse conditions, usually in the absence of pollinators. Thus, it is not clear to what extent self-fertilization occurs in nature. Rates of self-pollination in natural milkweed populations, on the other hand, have been investigated. Using genetic markers, self-pollination rates have been estimated to be as high as $67 \%$ for $A$. syriaca (Shore, 1993). Thus, in natural populations, pollination dynamics appear to impose few barriers to self-fertilization. In contrast, postpollination phenomena, such as self-incompatibility (Kephart, 1981; Wyatt et al., 1996) or inbreeding depression (Charlesworth \& Charlesworth, 1987), may be important in limiting self-fertilization in milkweeds.

So far, three species of Asclepias have been reported to lack self-incompatibility; nearly equal success has been reported from hand self-pollinations as from hand cross-pollinations in $A$. incarnata (Kephart, 1981), A. curassavica and $A$. fruticosa (Wyatt \& Broyles, 1997). Asclepias curassavica and $A$. fruticosa are both widely distributed, weedy milkweeds of the tropics. Asclepias incarnata, the focus of this study, is a perennial herb that occurs in wetlands throughout much of North America (Fig. 1). Plants often have multiple stems up to $2 \mathrm{~m}$ tall that emerge from a single root crown; each stem has multiple paired umbels with several pink- to rose-coloured flowers that are open simultaneously. Consequently, insects foraging among the umbels of individual plants could easily effect geitonogamous self-pollinations.

Woodson (1954) distinguished two subspecies of A. incarnata. Subspecies pulchra has broad, pubescent leaves, relatively unbranched stems, and ranges primarily along the Atlantic coast of North America east of the Blue Ridge Mountains (Fig. 1). In contrast, ssp. incarnata has linear-lanceolate leaves with little to no pubescence, freely branching upper stems, and ranges widely throughout the rest of the species range (Fig. 1). Rosatti (1989) pointed out that the genetic basis of the characters separating the subspecies has never been demonstrated and speculated that the characters that distinguish ssp.

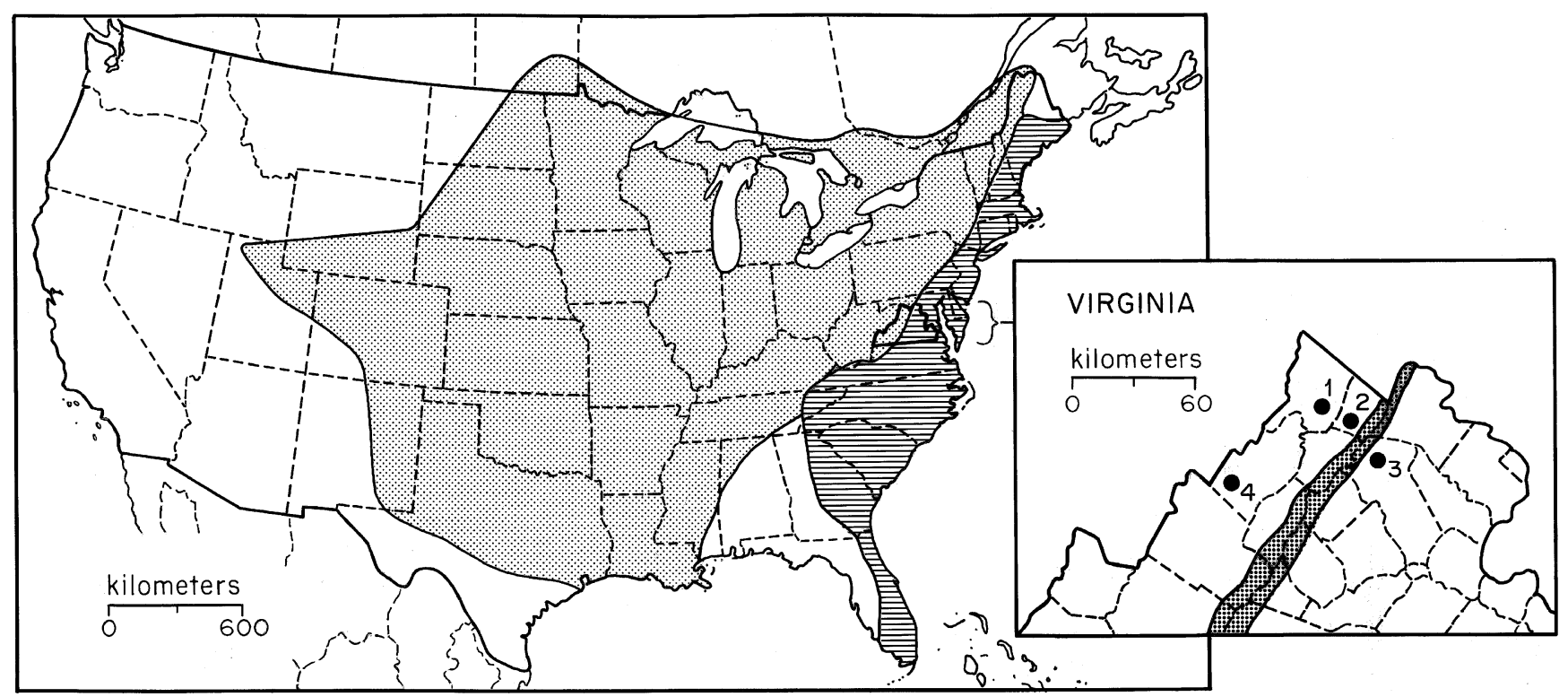

Fig. 1 Primary ranges of the two subspecies of Asclepias incarnata in North America, based on Woodson (1954): ssp. pulchra (shading with horizontal lines) and ssp. incarnata (stippled shading). Inset shows the location of study populations in northern Virginia. Populations numbered 1, 2 and 4 represent ssp. incarnata and are located in Frederick, Clarke and Shenandoah Cos, respectively. Population 3 represents ssp. pulchra and is located in Fauquier Co. The shaded area delineates the boundaries of the Blue Ridge physiographic region. 
pulchra may be induced by the brackish habitats in which it is sometimes found. Previous investigations into the breeding system of $A$. incarnata have not distinguished the subspecies studied (Fischer, 1941; Kephart, 1981).

Here we explore the mating system of $A$. incarnata more fully, by addressing the following questions. Are both subspecies of $A$. incarnata self-fertile? Are the subspecies interfertile? What is the outcrossing rate in natural populations of each subspecies? Does this vary among years and among populations? To address these questions, we conducted hand-pollinations of glasshouse-grown plants and conducted allozyme analyses on progeny arrays from naturally pollinated fruits.

\section{Materials and methods}

\section{Glasshouse hand-pollinations}

We grew 33 plants from seeds collected from 27 maternal plants representing four natural populations (number of maternal plants per population: Clarke $=6$, Fauquier $=8$, Frederick $=6$, Shenandoah $=7$ ) of swamp milkweed in northern Virginia (Fig. 1). Each plant was grown from a seed collected from a different fruit. Three of these populations, located in Clarke, Frederick and Shenandoah Cos, were ssp. incarnata. The fourth, located in Fauquier Co., was ssp. pulchra. Using dissecting needles, we removed pollinaria from donor flowers by carefully pulling the corpusculum toward the distal end of the flower until the pollinia were free. To prepare for insertion, the distal end of a single anther wing on a recipient flower was gently pushed slightly to one side, exposing the inside of the stigmatic chamber. A single pollinium was then slipped into the chamber with the convex surface of the pollinium toward the interior of the flower. After insertion, the anther wing was eased back into place (Wyatt, 1976; Wyatt et al., 1996). Only one stigmatic chamber per flower was pollinated. We pollinated three flowers per umbel, with each umbel receiving one of four treatments: (i) cross-pollination, using a pollinium from a different plant originating in the same population (within-population crosses); (ii) cross-pollination, using a pollinium from a plant originating in a different population (among-population crosses, which were only carried out for ssp. incarnata); (iii) cross-pollination, using a pollinium from a plant of the other subspecies; or (iv) self-pollination, using a pollinium from a different flower on the same plant.

From nine fruits of the successful intersubspecific crosses, representing three of the original popula- tions and seven of the original parental plants, we grew nine plants to maturity, one from each fruit. Hand-pollinations were performed as above, with umbels on the intersubspecific hybrid plants receiving one of three treatments: (i) cross-pollination, using a pollinium from ssp. incarnata; (ii) crosspollination, using a pollinium from ssp. pulchra; or (iii) self-pollination, using a pollinium from a separate flower on the same plant. In addition, we performed two other cross-pollination treatments: (i) using a pollinium from an intersubspecific hybrid plant to pollinate ssp. incarnata, and (ii) using a pollinium from an intersubspecific hybrid plant to pollinate ssp. pulchra. For all hand-pollinations we recorded the number of fruits developed and counted the number of seeds that were filled and unfilled. Filled seeds were those that had completely matured and contained fully developed cotyledons, whereas unfilled seeds were incompletely developed.

\section{Estimates of outcrossing rates from natural populations}

To estimate mating-system parameters in these natural populations, we used genetic markers from horizontal starch-gel electrophoresis. In the autumn of 1994 and 1995, we collected fruits from three of the populations previously used in the glasshouse study: ssp. incarnata (Clarke and Frederick Cos) and ssp. pulchra (Fauquier Co.). All three field sites were wet, abandoned pastures. Voucher specimens from each of these populations are housed in the University of Georgia Herbarium. In 1994, we collected 12 fruits from each of 25 plants in each of these populations. In 1995, we collected $\approx 15$ fruits from each of 26 plants in the Frederick and Fauquier Co. populations, and we collected $\approx 22$ fruits from each of 23 plants in the Clarke Co. population. Two seeds from each fruit were germinated and grown to the seedling stage. Cotyledons and leaves from one of the two seedlings were then crushed, using a ceramic mortar and glass pestle, with a chilled extraction buffer modified from Broyles \& Wyatt (1990) to include only $0.005 \%$ 2-mercaptoethanol. To ensure independence, we analysed only one seed from each fruit, as all seeds within milkweed fruits are typically full-sibs and result from a single mating event (Broyles \& Wyatt, 1990). The extract was filtered through Miracloth and absorbed onto $8 \times 3-\mathrm{mm}$ paper wicks cut from Whatman $3 \mathrm{~mm}$ chromatography paper. Sample wicks were stored at $-70^{\circ} \mathrm{C}$ until electrophoresis was performed.

Three electrophoretic buffer systems were used to resolve up to nine polymorphic allozyme loci. A 
continuous morpholine-citrate system ( $\mathrm{pH}$ 6.1: Broyles \& Wyatt, 1990) was used to resolve isocitrate dehydrogenase (IDH: EC 1.1.1.42) and phosphoglucoisomerase (PGI: EC 5.3.1.9). A continuous Tris-citrate system (electrode buffer: $0.3435 \mathrm{M}$ Tris, $0.0715 \mathrm{~m}$ citric acid monohydrate, $\mathrm{pH} 8.0$; gel buffer $6.68 \%$ dilution) was used to resolve fumarate hydratase (FUM: EC 4.2.1.2), leucine aminopeptidase (LAP: EC 3.4.-.-), phosphoglucomutase (PGM: EC 5.4.2.2) and fluorescent esterase (FLE: EC 3.1.1.-). A discontinuous buffer system with a lithium-borate electrode buffer and a Tris-citrate gel buffer ( $\mathrm{pH}$ 8.5: Broyles \& Wyatt, 1990) was used to resolve glutamic-oxaloacetic transaminase (GOT: EC 2.6.1.1), menadione reductase (MNR: EC 1.6.99.-) and triose-phosphate isomerase (TPI: EC 5.3.1.1). Protocols for resolving enzymes followed those described by Broyles \& Wyatt (1990).

Data were analysed using Ritland \& Jain's (1981) multilocus maximum likelihood model for estimating mating system parameters (MLTR version 1.1, 1996). Allozyme phenotypes of maternal plants were inferred for the Fauquier Co. population using the method of Brown \& Allard (1970). We directly observed the maternal allozyme phenotypes of the other populations by preparing extracts from adult leaves using the methods described above and subjecting these samples to identical electrophoretic treatments. In addition to multilocus outcrossing rate estimates, we estimated allele frequencies in the pollen pool and ovule pool, the population inbreeding coefficient ( $F$ : Wright, 1922), the frequency of biparental inbreeding, and correlations of outcross- ing and outcrossed paternity for siblings using the paired-sibling approach (Ritland, 1989). These parameters were estimated using an iterative maximum likelihood algorithm described by Ritland \& Jain (1981). Standard errors for parameters were estimated by 100 bootstraps of the data.

\section{Results}

\section{Glasshouse hand-pollinations}

We performed a total of 546 hand-pollinations on glasshouse parental plants. Within-population crosspollinations were 5.6 times more successful than self-pollinations (Table 1). Plants from ssp. incarnata populations were less successful at maturing fruits from both self- and cross-pollinations than plants from the ssp. pulchra population. Within-population crosses were 1.5 times more likely to result in a fruit than were between-population crosses in ssp. incarnata plants. Within-population crosses of ssp. incarnata plants were 14.5 times more successful than self-pollinations, whereas within-population crosses involving ssp. pulchra plants were 3.8 times more successful than self-pollinations.

The mean number of filled seeds differed little among treatments, except for a tendency toward lower seed-set in fruits from self-pollinations on ssp. incarnata plants (Table 1). Intersubspecific crosses in which ssp. pulchra plants were the maternal parent produced a higher proportion of unfilled seeds compared to the reciprocal crosses, but the number of filled seeds produced did not differ significantly between treatments.

Table 1 Fruit- and seed-set from hand-pollinations of Asclepias incarnata ssp. incarnata and A. i. ssp. pulchra. Pollinations were performed on plants grown in the glasshouse from seeds collected in four populations in northern Virginia

\begin{tabular}{lccccr}
\hline Type of pollination & $n$ & $\begin{array}{c}\text { Fruits } \\
\text { matured }\end{array}$ & $\begin{array}{c}\text { Percent } \\
\text { fruit-set }\end{array}$ & $\begin{array}{c}\text { Mean (SE) } \\
\text { filled seeds }\end{array}$ & $\begin{array}{c}\text { Mean (SE) } \\
\text { unfilled seeds }\end{array}$ \\
\hline Within ssp. incarnata & & & & & \\
$\quad$ Within populations & 72 & 30 & 41.67 & $60.7(2.1)$ & $3.7(1.0)$ \\
$\quad \begin{array}{l}\text { Between populations } \\
\text { Self-pollinations }\end{array}$ & 63 & 18 & 28.57 & $53.9(3.3)$ & $2.9(0.8)$ \\
Within ssp. pulchra & 105 & 3 & 2.86 & $52.3(2.3)$ & \\
$\quad$ Within populations & 63 & 39 & 61.91 & $60.3(1.3)$ & $1.4(0.3)$ \\
$\quad$ Self-pollinations & 93 & 15 & 16.13 & $59.1(1.8)$ & $3.0(0.9)$ \\
All within-pop. crosses & 135 & 69 & 51.11 & $60.5(1.7)$ & $2.5(0.5)$ \\
All self-pollinations & 198 & 18 & 9.09 & $57.9(1.6)$ & $2.4(0.8)$ \\
Between subspecies & & & & & \\
$\quad$ incarnata $\times$ pulchra & 81 & 26 & 32.10 & $53.1(2.8)$ & $3.2(1.2)$ \\
$\quad$ pulchra $\times$ incarnata & 69 & 19 & 27.54 & $51.9(3.9)$ & $19.5(5.8)$ \\
All interssp. crosses & 150 & 45 & 30.00 & $52.6(2.2)$ & $9.2(2.6)$ \\
\hline
\end{tabular}


We used 24 different plants as female pollen recipients. Success at fruit-set from both cross- and self-pollinations varied considerably among these plants (Table 2). We compared each plant's success at fruit maturation with fruit production in the remaining plants using Fisher's exact test of independence (Sokal \& Rohlf, 1981). Even though pollen sources sometimes differed among maternal plants, this test was justified because variation in male fertility has much less influence on fruit-set than does variation in female fertility for $A$. incarnata (S. R. Lipow \& R. Wyatt, unpubl. data). Five ssp. incarnata plants and one ssp. pulchra differed significantly from the other plants with respect to cross-pollinated fruit maturation (Table 2). Five of the 24 plants matured fruits from self-pollinations, but only two of all 24 self-pollinated plants differed significantly from the other plants with respect to self fruit production (Table 2).

We performed a total of 414 hand-pollinations involving intersubspecific hybrid plants. Of 21 nonhybrid plants involved in crosses as pollen recipients, 12 were ssp. incarnata and nine were ssp. pulchra. Overall, fruit-set from cross-pollinations was more than eight times higher than from self-pollinations (Table 3). Cross-pollinations in which hybrid plants served as maternal parents, however, were 4.3 times more successful than those in which hybrids served as pollen donors (Table 3 ). Cross-pollinations that used ssp. pulchra plants as maternal parents

Table 2 Success of individual Asclepias incarnata plants used as pollen recipients at cross- and self-fertilized fruit production following hand-pollinations in the glasshouse

\begin{tabular}{|c|c|c|c|c|c|c|}
\hline \multirow[b]{2}{*}{ Population } & \multicolumn{3}{|c|}{ Crosses } & \multicolumn{3}{|c|}{ Selfs } \\
\hline & $n$ & Fruits & $\%$ & $n$ & Fruits & $\%$ \\
\hline \multicolumn{7}{|l|}{ Clarke } \\
\hline 1 & 9 & 6 & 66.7 & 3 & 2 & $66.7^{*}$ \\
\hline 2 & 9 & 2 & 22.2 & 3 & 0 & 0.0 \\
\hline 3 & 9 & 1 & 11.1 & 3 & 1 & 33.3 \\
\hline 4 & 18 & 8 & 44.4 & 6 & 0 & 0.0 \\
\hline \multicolumn{7}{|l|}{ Fauquier } \\
\hline 1 & 9 & 4 & 44.4 & 6 & 0 & 0.0 \\
\hline 2 & 24 & 17 & $70.8^{* * *}$ & 18 & 12 & $66.7^{* * *}$ \\
\hline 3 & 12 & 4 & 33.3 & 6 & 0 & 0.0 \\
\hline 4 & 12 & 2 & 16.7 & 6 & 2 & 33.3 \\
\hline 5 & 36 & 17 & 47.2 & 27 & 1 & 3.7 \\
\hline 6 & 3 & 0 & 0.0 & 6 & 0 & 0.0 \\
\hline 7 & 18 & 7 & 38.9 & 12 & 0 & 0.0 \\
\hline 8 & 12 & 4 & 33.3 & 9 & 0 & 0.0 \\
\hline 9 & 6 & 3 & 50.0 & 3 & 0 & 0.0 \\
\hline \multicolumn{7}{|l|}{ Frederick } \\
\hline 1 & 18 & 13 & $72.2 * *$ & 6 & 0 & 0.0 \\
\hline 2 & 9 & 2 & 22.2 & 3 & 0 & 0.0 \\
\hline 3 & 27 & 4 & $14.8^{*}$ & 18 & 0 & 0.0 \\
\hline 4 & 27 & 1 & $3.7^{* * * *}$ & 15 & 0 & 0.0 \\
\hline 5 & 9 & 0 & $0.0^{*}$ & 9 & 0 & 0.0 \\
\hline \multicolumn{7}{|l|}{ Shenandoah } \\
\hline 1 & 18 & 6 & 33.3 & 6 & 0 & 0.0 \\
\hline 2 & 12 & 4 & 33.3 & 6 & 0 & 0.0 \\
\hline 3 & 18 & 14 & $77.8^{* * *}$ & 9 & 0 & 0.0 \\
\hline 4 & 3 & 0 & 0.0 & 3 & 0 & 0.0 \\
\hline 5 & 18 & 5 & 27.8 & 9 & 0 & 0.0 \\
\hline 6 & 12 & 8 & 66.7 & 6 & 0 & 0.0 \\
\hline Mean & 14.5 & 5.5 & 34.6 & 8.3 & 0.8 & 8.5 \\
\hline
\end{tabular}

${ }^{*} P<0.05,{ }^{*} P<0.01, * * * P<0.001$ in a two-tailed Fisher's exact test of independence comparing individual fruit production with that of other plants. 
Table 3 Fruit- and seed-set from hand-pollinations performed on intersubspecific hybrids of Asclepias incarnata ssp. incarnata and $A$. $i$. ssp. pulchra grown in the glasshouse

\begin{tabular}{lrrrrr}
\hline Type of pollination & $n$ & $\begin{array}{c}\text { No. } \\
\text { fruits }\end{array}$ & $\begin{array}{c}\text { Per cent } \\
\text { fruit-set }\end{array}$ & $\begin{array}{c}\text { Mean (SE) } \\
\text { filled seeds }\end{array}$ & $\begin{array}{c}\text { Mean (SE) } \\
\text { unfilled seeds }\end{array}$ \\
\hline Hybrid $\times$ ssp. incarnata & 66 & 35 & 53.03 & $59.7(1.8)$ & $4.2(1.1)$ \\
Hybrid $\times$ ssp. pulchra & 72 & 41 & 56.94 & $61.3(1.2)$ & $1.6(0.5)$ \\
Female hybrid success & 138 & 76 & 55.07 & $60.5(1.1)$ & $2.8(0.6)$ \\
Ssp. incarnata $\times$ hybrid & 66 & 5 & 7.58 & $52.0(5.6)$ & $0.2(0.2)$ \\
Ssp. pulchra $\times$ hybrid & 66 & 12 & 18.18 & $33.3(4.4)$ & $14.5(5.0)$ \\
Male hybrid success & 132 & 17 & 12.88 & $38.8(4.0)$ & $10.3(3.8)$ \\
All hybrid crosses & 270 & 93 & 34.44 & $56.6(1.4)$ & $4.2(0.9)$ \\
Hybrid selfs & 144 & 6 & 4.17 & $40.0(2.9)$ & $13.5(1.7)$ \\
\hline
\end{tabular}

produced more fruits than those that used ssp. incarnata plants as maternal parents, but fruits from maternal ssp. pulchra crosses contained fewer viable seeds than did fruits from maternal ssp. incarnata crosses.

Several of the crosses in which hybrids successfully pollinated ssp. pulchra resulted in unfilled seeds that had deformed seed coats or cotyledons that were shrivelled or that had begun to expand precociously. Seeds resulting from successful hybrid self-pollinations did not share these characteristics; note, however, that all of these seeds came from a single hybrid plant.

When hybrid plants were used as pollen recipients, individual fruit-set from cross-pollinations varied considerably; only two plants, however, differed significantly from the others at fruit maturation (Table 4). Only one of the hybrid plants succeeded at maturing fruits following self-pollinations. When hybrid plants were used as pollen donors, fruit-set from cross-pollinations was uniformly lower than when hybrids were used as pollen recipients; one plant was significantly more successful than the others at siring fruits (Table 4). There was no apparent pattern of hybrid pollen fertility associated with the direction of the intersubspecific hybrid cross. Pollinia from nine plants, three each of ssp. incarnata, ssp. pulchra and hybrids all germinated after soaking for $3 \mathrm{~h}$ in a $30 \%$ sucrose solution.

\section{Estimates of outcrossing rates from natural populations}

Estimated allele frequencies in the pollen and ovule pools revealed ample polymorphism to allow robust

Table 4 Success of individual intersubspecific hybrid plants of Asclepias incarnata at fruit production following hand-pollinations in the glasshouse

\begin{tabular}{|c|c|c|c|c|c|c|c|c|c|}
\hline \multirow[b]{2}{*}{ Plant } & \multicolumn{3}{|c|}{ Pollen donor } & \multicolumn{3}{|c|}{ Pollen recipient } & \multicolumn{3}{|c|}{ Selfs } \\
\hline & $n$ & Fruits & $\%$ & $n$ & Fruits & $\%$ & $n$ & Fruits & $\%$ \\
\hline 1 & 12 & 4 & $33.3^{*}$ & 12 & 10 & 83.3 & 12 & 0 & 0.0 \\
\hline 2 & 18 & 1 & 5.6 & 18 & 8 & 44.4 & 18 & 0 & 0.0 \\
\hline 3 & 18 & 2 & 11.1 & 21 & 10 & 47.6 & 24 & 0 & 0.0 \\
\hline 4 & 6 & 0 & 0.0 & 9 & 1 & $11.1^{*}$ & 12 & 0 & 0.0 \\
\hline 5 & 6 & 0 & 0.0 & 6 & 1 & 16.7 & 6 & 0 & 0.0 \\
\hline 6 & 12 & 2 & 16.7 & 12 & 9 & 75.0 & 12 & 0 & 0.0 \\
\hline 7 & 18 & 2 & 11.1 & 18 & 14 & $77.8^{*}$ & 18 & 0 & 0.0 \\
\hline 8 & 18 & 4 & 22.2 & 18 & 13 & 72.2 & 18 & 6 & $33.3^{* *}$ \\
\hline 9 & 24 & 2 & 8.3 & 24 & 10 & 41.7 & 24 & 0 & 0.0 \\
\hline Mean & 14.6 & 1.9 & 12.0 & 15.3 & 8.4 & 52.2 & 16 & 0.7 & 3.7 \\
\hline
\end{tabular}

${ }^{*} P<0.05,{ }^{*} P<0.01,{ }^{* * *} P<0.001$ in a two-tailed Fisher's exact test of independence comparing individual fruit production with that of other plants. 
estimates of population mating-system parameters in the natural populations (Table 5). We were able to score Fum-1 only in 1994 for the Frederick and Fauquier Co. populations and only in 1995 for the Clarke Co. population because of poor resolution. Similarly, we were unable to score Lap-1 reliably for the Fauquier Co. population in 1995. Nonetheless, the remaining loci were well resolved and the progeny arrays displayed banding patterns consistent with expected inheritance patterns based on maternal isozyme phenotype.

There was considerable variation within and among populations in the estimates of pollen and ovule allele frequencies. For three of the loci (Fle-1 in Clarke Co., Lap-1 in Frederick Co. and Pgi-1 in Fauquier Co.), there were substantial between-year differences in allele frequencies within a single population (Table 5). Four loci (Got-2, Idh-1, Lap-1 and Pgi-1) indicated large differences in allele frequencies between the two ssp. incarnata populations and between the two subspecies. All three populations contained unique alleles (Clarke: Fum-1a, Fum-1b; Frederick: Mnr-2c; Fauquier: Idh-1c, Mnr-2a), each of which was in very low frequency except for $I d h-1 c$ in the Fauquier Co. population. We did not find any fixed allelic differences between the two subspecies.

Inbreeding coefficients were not significantly different from zero for any population in either year (Table 6). Multilocus outcrossing rate estimates for all three populations were high, but significantly $<1.0$ for the Fauquier Co. population of ssp. pulchra in both years and for the Frederick Co. population of ssp. incarnata only in 1995 . The difference between multilocus and single-locus estimates of outcrossing rate provides an estimate of biparental inbreeding (Shaw \& Allard, 1982), and these were not significantly different from zero in any population in either year. Correlations for outcrossing $\left(r_{\mathrm{t}}\right)$ among progeny pairs varied widely among populations and among years. Standard errors of these estimates for $r_{\mathrm{t}}$ were large, however, and none was significantly different from zero for any population, suggesting little variation among families for outcrossing rate (Ritland, 1989). Correlations for outcrossed paternity $\left(r_{\mathrm{p}}\right)$ among progeny pairs were moderately high for the ssp. incarnata populations in both years, but they were significantly $>0$ in the ssp. pulchra population only in 1995. A positive value for $r_{\mathrm{p}}$ suggests that not all potential fathers are represented equally in the pollen pool (Ritland, 1989), which may happen if pollen movement is localized or floral display sizes differ (Broyles \& Wyatt, 1990). Both single-locus and multilocus outcrossing rate estimates were slightly lower in 1995 for all three populations, but not significantly so. In both years, the Clarke Co. population had the highest and the Fauquier Co. population had the lowest estimate of outcrossing rate. None of the differences in outcrossing rates among populations was statistically significant.

\section{Discussion}

The two subspecies of swamp milkweed retained their distinctive characteristics when plants grown from naturally pollinated seeds of each subspecies were maintained in the glasshouse under identical conditions. Thus, we reject Rosatti's (1989) hypothesis that the characters distinguishing these subspecies are environmentally induced. We found the two subspecies to be freely interfertile, but the male fertility of intersubspecific hybrid plants was reduced relative to parental plants, possibly indicating 'hybrid breakdown' in the progeny of these crosses. Hybrid pollen readily germinated in vitro; thus, the basis for reduced fertility is unclear.

Reduced pollen fertility has been reported previously in milkweed hybrids. Pollen sterility was found in interspecific hybrids between $A$. perennis and $A$. texana (R. Wyatt, A. L. Edwards, S. R. Lipow \& C. T. Ivey, unpubl. data). Woodson (1954) placed these two species, along with $A$. incarnata, in the 'natural and primitive' series Incarnatae of Asclepias. Interspecific hybrids of $A$. exaltata and $A$. purpurascens also had reduced pollen viability relative to parental plants (S. B. Broyles \& R. Wyatt, unpubl. data). These species were placed in series Exaltatae and Purpurascentes, respectively. Thus, it appears that the phenomenon of reduced pollen fertility in milkweed hybrids is not restricted to crosses among species within series Incarnatae. Based on the data currently available, hybridization and introgression appear to be unusual among milkweeds in nature (Wyatt \& Broyles, 1994). Our data, in conjunction with previous reports, suggest that this may be caused in part by reduced fitness in $\mathrm{F}_{1}$ hybrid plants.

In the region in which this study was conducted, the Blue Ridge Mountains delineate the primary ranges of the two subspecies (Woodson, 1954). The majority of populations west of the Blue Ridge Mountains are ssp. incarnata, whereas most of the populations east of the Blue Ridge are ssp. pulchra. No Virginia populations of $A$. incarnata are known to occur at elevations as high as the crest of the Blue Ridge (Woodson, 1954). Because this mountain range is not an absolute boundary for the subspecies ranges, however, there is potential for 
Table 5 Estimated pollen and ovule allele frequencies in three populations of Asclepias incarnata from northern Virginia in 1994 and 1995. Standard errors (indicated in parentheses) were estimated by 100 bootstraps of the data. Populations from Clarke and Frederick Cos are ssp. incarnata whereas the population from Fauquier Co. is ssp. pulchra

\begin{tabular}{|c|c|c|c|c|c|c|c|c|c|c|c|c|c|}
\hline \multirow[b]{2}{*}{ Locus } & \multirow[b]{2}{*}{ Allele } & \multicolumn{2}{|c|}{ Clarke 1994} & \multicolumn{2}{|c|}{ Clarke 1995} & \multicolumn{2}{|c|}{ Frederick 1994} & \multicolumn{2}{|c|}{ Frederick 1995} & \multicolumn{2}{|c|}{ Fauquier 1994} & \multicolumn{2}{|c|}{ Fauquier 1995} \\
\hline & & Pollen & Ovule & Pollen & Ovule & Pollen & Ovule & Pollen & Ovule & Pollen & Ovule & Pollen & Ovule \\
\hline \multirow[t]{3}{*}{ Fle-1 } & $a$ & $0.103(0.020)$ & $0.082(0.034)$ & $0.358(0.025)$ & $0.413(0.084)$ & $0.222(0.036)$ & $0.250(0.061)$ & $0.226(0.038)$ & $0.346(0.067)$ & $0.653(0.061)$ & $0.745(0.076)$ & $0.709(0.038)$ & $0.750(0.045)$ \\
\hline & $b$ & $0.875(0.020)$ & $0.898(0.034)$ & $0.642(0.025)$ & $0.587(0.084)$ & $0.742(0.048)$ & $0.712(0.059)$ & $0.749(0.039)$ & $0.596(0.060)$ & $0.343(0.061)$ & $0.235(0.076)$ & $0.291(0.038)$ & $0.250(0.045)$ \\
\hline & $c$ & $0.022(0.012)$ & $0.020(0.000)$ & - & - & $0.035(0.026)$ & $0.038(0.024)$ & $0.026(0.010)$ & $0.058(0.030)$ & $0.004(0.004)$ & $0.020(0.001)$ & - & - \\
\hline \multirow[t]{4}{*}{ Fum-1 } & $a$ & - & - & $0.016(0.007)$ & $0.021(0.002)$ & - & - & - & - & - & - & - & - \\
\hline & $b$ & - & - & $0.074(0.017)$ & $0.064(0.034)$ & - & - & - & - & - & - & - & - \\
\hline & $c$ & - & - & $0.911(0.018)$ & $0.915(0.034)$ & $0.976(0.012)$ & $0.981(0.013)$ & - & - & $0.878(0.026)$ & $0.900(0.035)$ & - & - \\
\hline & $d$ & - & - & - & - & $0.024(0.012)$ & $0.019(0.013)$ & - & - & $0.122(0.026)$ & $0.100(0.035)$ & - & - \\
\hline \multirow[t]{3}{*}{ Got-2 } & $a$ & $0.226(0.031)$ & $0.184(0.068)$ & $0.165(0.023)$ & $0.109(0.045)$ & $0.591(0.054)$ & $0.660(0.064)$ & $0.546(0.042)$ & $0.558(0.077)$ & $0.949(0.016)$ & $0.960(0.024)$ & $0.869(0.023)$ & $0.786(0.042)$ \\
\hline & $b$ & $0.767(0.034)$ & $0.796(0.068)$ & $0.831(0.023)$ & $0.870(0.047)$ & $0.402(0.054)$ & $0.321(0.064)$ & $0.434(0.042)$ & $0.385(0.072)$ & $0.051(0.016)$ & $0.040(0.024)$ & $0.131(0.023)$ & $0.214(0.042)$ \\
\hline & $c$ & $0.007(0.007)$ & $0.020(0.000)$ & $0.003(0.002)$ & $0.022(0.016)$ & $0.006(0.004)$ & $0.019(0.000)$ & $0.020(0.012)$ & $0.058(0.027)$ & - & - & - & - \\
\hline \multirow[t]{4}{*}{$I d h-1$} & $a$ & $0.288(0.057)$ & $0.417(0.070)$ & $0.214(0.030)$ & $0.217(0.059)$ & $0.116(0.027)$ & $0.058(0.033)$ & $0.104(0.020)$ & $0.154(0.049)$ & $0.004(0.003)$ & $0.020(0.001)$ & - & - \\
\hline & $b$ & $0.458(0.044)$ & $0.417(0.061)$ & $0.507(0.033)$ & $0.609(0.071)$ & $0.596(0.057)$ & $0.558(0.074)$ & $0.501(0.042)$ & $0.442(0.079)$ & $0.653(0.040)$ & $0.745(0.065)$ & $0.668(0.037)$ & $0.679(0.047)$ \\
\hline & $c$ & - & - & - & - & - & - & - & - & $0.343(0.040)$ & $0.235(0.065)$ & $0.280(0.033)$ & $0.286(0.050)$ \\
\hline & $d$ & $0.253(0.036)$ & $0.167(0.052)$ & $0.278(0.036)$ & $0.174(0.054)$ & $0.288(0.053)$ & $0.385(0.082)$ & $0.394(0.044)$ & $0.404(0.090)$ & - & - & $0.051(0.019)$ & $0.036(0.022)$ \\
\hline \multirow[t]{4}{*}{ Lap-1 } & $a$ & - & - & - & - & $0.571(0.050)$ & $0.231(0.064)$ & - & - & $0.244(0.050)$ & $0.216(0.058)$ & - & - \\
\hline & $b$ & $0.946(0.015)$ & $0.917(0.040)$ & $0.991(0.004)$ & $0.978(0.016)$ & $0.329(0.048)$ & $0.615(0.066)$ & $0.744(0.033)$ & $0.885(0.036)$ & $0.546(0.055)$ & $0.549(0.047)$ & - & - \\
\hline & $c$ & $0.054(0.015)$ & $0.083(0.040)$ & $0.009(0.004)$ & $0.022(0.016)$ & $0.094(0.024)$ & $0.135(0.042)$ & $0.241(0.035)$ & $0.096(0.035)$ & $0.196(0.045)$ & $0.216(0.058)$ & - & - \\
\hline & $d$ & - & - & - & - & $0.006(0.001)$ & $0.019(0.014)$ & $0.015(0.006)$ & $0.019(0.012)$ & $0.013(0.007)$ & $0.020(0.001)$ & - & - \\
\hline \multirow[t]{3}{*}{ Mnr-2 } & $a$ & - & - & - & - & - & - & - & - & $0.004(0.000)$ & $0.020(0.013)$ & $0.003(0.002)$ & $0.018(0.001)$ \\
\hline & $b$ & $1.000(0.000)$ & $1.000(0.000)$ & $1.000(0.000)$ & $1.000(0.000)$ & $0.994(0.001)$ & $0.981(0.016)$ & $1.000(0.000)$ & $1.000(0.000)$ & $0.996(0.000)$ & $0.980(0.013)$ & $0.997(0.002)$ & $0.982(0.002)$ \\
\hline & $c$ & - & - & - & - & $0.006(0.001)$ & $0.019(0.016)$ & - & - & - & - & - & - \\
\hline \multirow[t]{4}{*}{ Pgi-1 } & $a$ & - & - & - & - & - & - & $0.006(0.004)$ & $0.019(0.001)$ & $0.052(0.021)$ & $0.060(0.032)$ & - & - \\
\hline & $b$ & $0.115(0.033)$ & $0.021(0.012)$ & $0.036(0.009)$ & $0.064(0.034)$ & $0.047(0.017)$ & $0.038(0.026)$ & $0.081(0.020)$ & $0.037(0.023)$ & $0.189(0.027)$ & $0.280(0.052)$ & $0.458(0.038)$ & $0.304(0.066)$ \\
\hline & $c$ & $0.885(0.033)$ & $0.979(0.012)$ & $0.951(0.012)$ & $0.915(0.034)$ & $0.953(0.017)$ & $0.962(0.026)$ & $0.907(0.021)$ & $0.926(0.023)$ & $0.737(0.029)$ & $0.640(0.056)$ & $0.542(0.038)$ & $0.696(0.066)$ \\
\hline & $d$ & - & - & $0.013(0.007)$ & $0.021(0.002)$ & - & $\frac{0.002(0.020)}{-}$ & $0.006(0.004)$ & $0.019(0.001)$ & $0.022(0.010)$ & $0.020(0.019)$ & $\begin{array}{c}-.0+2(0.070) \\
-\end{array}$ & - \\
\hline \multirow[t]{3}{*}{ Pgm-1 } & $a$ & $0.185(0.027)$ & $0.208(0.048)$ & $0.285(0.030)$ & $0.370(0.074)$ & $0.035(0.016)$ & $0.019(0.018)$ & $0.003(0.000)$ & $0.019(0.010)$ & $0.131(0.032)$ & $0.098(0.046)$ & $0.020(0.009)$ & $0.018(0.012)$ \\
\hline & $b$ & $0.815(0.027)$ & $0.792(0.048)$ & $0.715(0.030)$ & $0.630(0.074)$ & $0.906(0.025)$ & $0.962(0.018)$ & $0.997(0.001)$ & $0.981(0.010)$ & $0.856(0.032)$ & $0.882(0.046)$ & $0.980(0.009)$ & $0.982(0.012)$ \\
\hline & $c$ & - & - & - & - & $0.059(0.018)$ & $0.019(0.001)$ & - & - & $0.013(0.006)$ & $0.020(0.001)$ & - & $\frac{0.702(0.012)}{-}$ \\
\hline \multirow[t]{2}{*}{$T p i-2$} & $a$ & $0.168(0.028)$ & $0.167(0.041)$ & $0.228(0.029)$ & $0.261(0.066)$ & $0.165(0.034)$ & $0.058(0.031)$ & $0.117(0.019)$ & $0.058(0.028)$ & $0.004(0.003)$ & $0.020(0.015)$ & $0.003(0.002)$ & $0.018(0.012)$ \\
\hline & $b$ & $0.832(0.028)$ & $0.833(0.041)$ & $0.772(0.029)$ & $0.739(0.066)$ & $0.835(0.034)$ & $0.942(0.031)$ & $0.883(0.019)$ & $0.942(0.028)$ & $0.996(0.003)$ & $0.980(0.015)$ & $0.997(0.002)$ & $0.982(0.012)$ \\
\hline
\end{tabular}


Table 6 Mating system parameter estimates inferred from allozyme patterns of open-pollinated progeny arrays in three populations of Asclepias incarnata from northern Virginia. Estimates of the standard error were obtained from 100 bootstraps of the data and follow parameter estimates in parentheses

\begin{tabular}{|c|c|c|c|c|c|c|}
\hline & $F$ & $t_{\mathrm{m}}$ & $t_{\mathrm{s}}$ & $t_{\mathrm{m}}-t_{\mathrm{s}}$ & $r_{\mathrm{t}}$ & $r_{\mathrm{p}}$ \\
\hline \multicolumn{7}{|c|}{$\begin{array}{l}\text { Clarke Co. } \\
\text { (ssp. incarnata) }\end{array}$} \\
\hline 1994 & $-0.056(0.137)$ & $0.986 \dagger(0.034)$ & $0.965 \dagger(0.036)$ & $0.021 \dagger(0.022)$ & $-0.758(0.710)$ & $0.231 \dagger(0.049)$ \\
\hline 1995 & $-0.009(0.094)$ & $0.959 \dagger(0.020)$ & $0.957 \dagger(0.030)$ & $0.002 \dagger(0.017)$ & $-0.006(0.133)$ & $0.186 \dagger(0.033)$ \\
\hline \multicolumn{7}{|c|}{$\begin{array}{l}\text { Frederick Co. } \\
\text { (ssp. incarnata) }\end{array}$} \\
\hline 1994 & $0.135(0.077)$ & $0.946 \dagger(0.030)$ & $0.905 \dagger(0.038)$ & $0.041 \dagger(0.034)$ & $-0.053(0.308)$ & $0.396 \dagger(0.075)$ \\
\hline 1995 & $0.001(0.067)$ & $0.926 \dagger(0.023)$ & $0.867 \dagger(0.033)$ & $0.058 \dagger(0.024)$ & $-0.085(0.055)$ & $0.311 \dagger(0.036)$ \\
\hline \multicolumn{7}{|c|}{$\begin{array}{l}\text { Fauquier Co. } \\
\text { (ssp. pulchra) }\end{array}$} \\
\hline 1994 & $-0.139(0.191)$ & $0.892 \dagger(0.049)$ & $0.857 \dagger(0.053)$ & $0.035 \dagger(0.029)$ & $0.372(0.316)$ & $0.188(0.210)$ \\
\hline 1995 & $-0.165(0.287)$ & $0.881 \dagger(0.047)$ & $0.829 \dagger(0.054)$ & $0.052 \dagger(0.023)$ & $0.071(0.199)$ & $0.315 \dagger(0.077)$ \\
\hline
\end{tabular}

$F$, inbreeding coefficient; $t_{\mathrm{m}}$, multilocus outcrossing rate; $t_{\mathrm{s}}$, mean of single-locus outcrossing rates; $t_{\mathrm{m}}-t_{\mathrm{s}}$, difference between multilocus and single-locus estimates of outcrossing; $r_{\mathrm{t}}$, correlation between progeny pairs for outcrossing; $r_{\mathrm{p}}$, correlation between progeny pairs for outcrossed paternity.

$\dagger$ Parameters that were re-estimated after other parameters were constrained to 0 to increase estimation power.

pollen or seed movement between populations of subspecies that exist on the same side of these mountains. The combination of geographical barriers and lower fertility of hybrids, however, may be sufficient to maintain the two subspecies.

Both subspecies of $A$. incarnata produced fruits from hand self-pollinations in experimental glasshouse crosses. In contrast to Kephart's (1981) observation of nearly equivalent success, however, both subspecies matured more fruits from cross- than from self-pollinations. We found that within-population crosses of ssp. incarnata plants were 1.5 times more successful than crosses between populations. Kephart (1981) reported within-population crosses to be only about one-half as successful as those between populations, a pattern that could be explained by inbreeding depression if plants within a population are more closely related than plants from different populations. The populations of ssp. incarnata that we studied were large and did not appear to be significantly inbred; thus, it is not surprising that we saw no indication of population-level inbreeding depression. If anything, our results point to the possibility of outbreeding depression (sensu Waser \& Price, 1994). It seems unlikely, however, that plants as highly vagile as milkweeds would suffer from outbreeding depression (cf. Broyles \& Wyatt, 1990).

As was true for our results from hand self-pollinations in the glasshouse, our estimates based on allozyme variation in open-pollinated progeny arrays suggest that maturation of self-fertilized fruits is unusual in natural populations of both subspecies. Geitonogamy is probably very high for swamp milkweed, as it is for other milkweeds (Shore, 1993). Thus, postpollination phenomena, such as competition-dependent fruit abscission (Becerra \& Lloyd, 1992), may be important in determining outcrossing rate in this species. Multilocus estimates of outcrossing were high for all three populations in both years. Our low estimates of inbreeding coefficients and biparental inbreeding also support the view that these populations are largely outcrossed. Nevertheless, through paternity exclusion analysis, we have found that self-fertilized fruits are produced in natural populations: we discovered that nine of 62 $(14.5 \%)$ fruits from 13 maternal plants were derived from self-fertilization in a natural population of $A$. incarnata (unpubl. data). It is important to note that the populations that we studied all occurred within a radius of $\approx 30 \mathrm{~km}$ and represent only a small portion of the range of this widespread species. It is possible that its mating system varies more than we observed across this limited portion of its range (see below).

Estimates of correlation for outcrossing $\left(r_{t}\right)$ varied widely, but had large standard errors and, as a consequence, were not significantly different from zero in any population. The large standard errors may indicate that the data did not conform well to model assumptions, which could occur if mating events involve parents that are both heterozygous at multiple loci. In any case, these observations suggest 
that there is little variation among plants in outcrossing rate. This was somewhat unexpected, as some of the plants grown in the glasshouse varied significantly in their propensity to mature self-fertilized fruits, even under controlled conditions. Furthermore, estimates of family level outcrossing rates vary greatly in all three of these populations (unpubl. data). Others have found, however, that much of the apparent variation in estimates of family-level outcrossing rate is merely the result of statistical variation (Morgan \& Barrett, 1990). Thus, it is still unclear how much individual swamp milkweed plants vary in outcrossing rate in nature.

Overall, our data suggest that mating systems of milkweeds are more complex than previously supposed. Swamp milkweed appears to be capable of self-fertilization, but cross-pollinations are more successful than self-pollinations in both glasshouse and natural environments. Thus, $A$. incarnata does not fit squarely into either of the categories of milkweed breeding systems (fully self-compatible or nearly self-incompatible) distinguished by Wyatt \& Broyles (1994). Some previous data also support the view that mating systems in milkweeds are more complex than previously believed. For example, low levels of self-compatibility have been observed in several milkweed species that are generally regarded as self-incompatible (Wyatt, 1976; Wyatt et al., 1996)

Although self-incompatibility in milkweeds appears to have a simple genetic basis (S. R. Lipow \& R. Wyatt, unpubl. data), variation in self-compatibility among individuals or populations may result from the expression of alleles that modify the selfincompatibility system (e.g. 'pseudo-self-fertility': Levin, 1996). Differences among populations in the frequencies of such modifier alleles could explain why the fruit-set we observed from hand self-pollinations in the glasshouse was less successful than that reported by Kephart (1981). Indeed, variation among populations in the frequency of self-fertile plants has been observed even within a milkweed species previously characterized as 'self-incompatible' (A. exaltata: S. R. Lipow \& R. Wyatt, unpubl. data).

Levin (1996) contends that alleles modifying selfincompatibility systems are common in plants and that they play an important role in the evolution of self-compatibility. Indeed, the shift from self-incompatibility to self-compatibility can result from an increase in the frequency of such alleles (Levin, 1996). Under such circumstances, complexity in plant mating systems is likely to be the rule; some workers have gone so far as to suggest that the variation observed in self-fertility in some taxa should be viewed as a quantitative trait (Mulcahy, 1984).

As is true for many other plant genera (Stebbins, 1974), self-compatibility in milkweeds appears to have had multiple origins; it has been reported in three species representing two of Woodson's (1954) eight taxonomic series of subgenus Asclepias. It is possible that variation in self-compatibility is more widespread than is currently believed, as the breeding systems of only 10 of the 108 species of Asclepias have been studied. Moreover, all of the milkweed species investigated fall into only one of the nine subgenera (Asclepias) distinguished by Woodson (1954). We expect that further investigation into the distribution of self-compatibility in this large genus will provide insight into its origins.

\section{Acknow ledgements}

We thank P. M. Dixon, J. L. Hamrick, R. R. Sharitz, T. J. Crawford and two anonymous reviewers for suggesting improvements to earlier versions of this manuscript. Excellent glasshouse care was provided for our plants by K. Davis and A. Tull. We are indebted to C. Hahn for careful preparation of the figure. This research was supported in part by grants to C.T.I. from the American Museum of Natural History Theodore Roosevelt Memorial Fund, Sigma $\mathrm{Xi}$, the University of Georgia Botany Department Palfrey Fund, and the University of Virginia's Blandy Experimental Farm.

\section{References}

BeCERrA, J. X. AND LlOYD, D. G. 1992. Competitiondependent abscission of self-pollinated flowers of Phormium tenax (Agavaceae): a second action of self-incompatibility at the whole flower level? Evolution, 46, 458-469.

BROWN, A. H. D. AND ALlARD, R. W. 1970. Estimation of the mating system in open-pollinated maize populations using isozyme polymorphisms. Genetics, 66, 133-145.

BROYLES, S. B. AND WYATT, R. 1990. Paternity analysis in a natural population of Asclepias exaltata: multiple paternity, functional gender, and the 'pollen-donation hypothesis.' Evolution, 44, 1454-1468.

CHARLESWORTH, D. AND CHARLESWORTH, B. 1987. Inbreeding depression and its evolutionary consequences. Ann. Rev. Ecol. Syst., 18, 237-268.

FISCHER, E. 1941. Der Anbau einer Faser- und BienenFutterpflanze. Pflanzenbau, 17, 212-218.

HAMRICK, J. L. AND GODT, M. J. W. 1990. Allozyme diversity in plant species. In: Brown, A. H. D., Clegg, M. T., Kahler, A. L. and Weir, B. S. (eds) Plant Population 
Genetics, Breeding and Genetic Resources, pp. 43-63. Sinauer, Sunderland, MA.

HILDEBRAND, R. 1866. Über die Befruchtung von Asclepias cornutii. Bot. Zeit., 24, 376-378.

JARNE, P. AND CHARLESWORTH, D. 1993. The evolution of the selfing rate in functionally hermaphrodite plants and animals. Ann. Rev. Ecol. Syst., 24, 441-466.

KEPHART, S. R. 1981. Breeding systems in Asclepias incarnata L., A. syriaca L. and A. verticillata L. Am. J. Bot., 68, 226-232.

LEVIN, D. A. 1996. The evolutionary significance of pseudoself-fertility. Am. Nat., 148, 321-332.

MORGAN, M. T. AND BARRETT, S. C. H. 1990. Outcrossing rates and correlated mating within a population of Eichhornia paniculata (Pontederiaceae). Heredity, 64, 271-280.

MULCAHY, D. L. 1984. The relationships between selfincompatibility, pseudo-compatibility and self-compatibility. In: Grant, W. F. (ed.) Plant Biosystematics, pp. 229-235. Academic Press, Toronto.

RITLAND, K. 1989. Correlated matings in the partial selfer Mimulus guttatus. Evolution, 43, 848-859.

RITLAND, K. AND JAIN, s. K. 1981. A model for the estimation of outcrossing rate and gene frequencies using $n$ independent loci. Heredity, 47, 35-52.

RosatTi, T. J. 1989. The genera of suborder Apocynineae (Apocynaceae and Asclepiadaceae) in the southeastern United States. J. Arnold Arboretum, 70, 443-514.

SHAW, D. V. AND ALLARD, R. W. 1982. Estimation of outcrossing rates in Douglas-fir using isozyme markers. Theor. Appl. Genet., 62, 115-121.
SHORE, J. S. 1993. Pollination genetics of the common milkweed, Asclepias syriaca L. Heredity, 70, 101-108.

SOKAL, R. R. AND ROHLF, F. J. 1981. Biometry, 2nd edn. W. H. Freeman, San Francisco.

SteBbins, G. L. 1974. Flowering Plants: Evolution above the Species Level. Belknap, Cambridge, MA.

stevens, O. A. 1945. Cultivation of milkweed. N. Dak. Agr. Exp. Sta. Bull., 33, 1-19.

WASER, N. M. AND PRICE, M. V. 1994. Crossing distance effects in Delphinium nelsonii: outbreeding and inbreeding depression in progeny fitness. Evolution, 48, 842-852.

woodson, R. E. 1954. The North American species of Asclepias L. Ann. Mo. Bot. Gard., 41, 1-211.

WRIGHT, s. 1922. Coefficients of inbreeding and relationship. Am. Nat., 56, 330-338.

WYATT, R. 1976. Pollination and fruit-set in Asclepias: a reappraisal. Am. J. Bot., 63, 845-851.

WYATT, R. 1988. Phylogenetic aspects of the evolution of self-pollination. In: Gottlieb, L. D. and Jain, S. K. (eds) Plant Evolutionary Biology, pp. 109-131. Chapman \& Hall, London.

WYATT, R. AND BROYLES, S. B. 1994. Ecology and evolution of reproduction in milkweeds. Ann. Rev. Ecol. Syst., 25, 423-441.

WYATT, R. AND BROYLES, S. B. 1997. The weedy tropical milkweeds Asclepias curassavica and A. fruticosa are self-compatible. Biotropica, 29, 232-234.

WYATT, R., IVEY, C. T. AND LIPOW, S. R. 1996. The breeding system of desert milkweed, Asclepias subulata. Bull. Torrey Bot. Club, 120, 177-179. 